\title{
Treatment of asthma with lipid extract of New Zealand green-lipped mussel: a randomised clinical trial
}

\author{
A. Emelyanov*, G. Fedoseev*, O. Krasnoschekova*, A. Abulimity*, T. Trendeleva*, P.J. Barnes ${ }^{\#}$
}

Treatment of asthma with lipid extract of New Zealand green-lipped mussel: a randomised clinical trial. A. Emelyanov, G. Fedoseev, O. Krasnoschekova, A. Abulimity, T. Trendeleva, P.J. Barnes. C)ERS Journals Ltd 2002.

ABSTRACT: Asthma is a chronic inflammatory disease of the airways mediated, at least in part, by leukotrienes and other lipid mediators. Experimental studies have shown that lipid extract of New Zealand green-lipped mussel, Perna canaliculus, is effective in inhibiting $5^{\prime}$-lipoxygenase and cyclo-oxygenase pathways responsible for production of eicosanoids, including leukotrienes and prostaglandins. The aim of this study was to assess its effect on symptoms, peak expiratory flow (PEF) and hydrogen peroxide $\left(\mathrm{H}_{2} \mathrm{O}_{2}\right)$ in expired breath condensate as a marker of airway inflammation in patients with steroid-naïve atopic asthma in a double-blind randomised, placebocontrolled clinical trial.

Forty six patients with atopic asthma received two capsules of lipid extract (Lyprinol $(\mathbb{R})$ or placebo b.i.d. for 8 weeks. Each capsule of lipid extract contained $50 \mathrm{mg} \omega-3$ polyunsaturated fatty acids and $100 \mathrm{mg}$ olive oil, whereas placebo capsules contained only $150 \mathrm{mg}$ olive oil.

There was a significant decrease in daytime wheeze, the concentration of exhaled $\mathrm{H}_{2} \mathrm{O}_{2}$ and an increase in morning PEF in the lipid extract group compared to the placebo group. There were no significant side-effects.

The authors conclude that lipid extract of New Zealand green-lipped mussel may have some beneficial effect in patients with atopic asthma. Eur Respir J 2002; 20: 596-600.
*Hospital Therapeutic Clinic, Pavlov Medical University, St-Petersburg, Russia. ${ }^{\#}$ Dept of Thoracic Medicine, National Heart and Lung Institute, London, UK.

\section{Correspondence: A. Emelyanov}

Hospital Therapeutic Clinic

Pavlov Medical University

6/8 L.Tolstogo Str

St-Petersburg 197089

Russia

Fax: 78122342749

E-mail: emelav@netscape.net

\section{Keywords: Asthma \\ green-lipped mussel lipid extract}

treatment

Received: December 192001

Accepted after revision: April 182002
Asthma is a chronic inflammatory disease of the airways mediated, at least in part, by leukotrienes and other lipid mediators. Experimental studies have shown that lipid extract of the New Zealand greenlipped mussel (Perna canaliculus) is effective at inhibiting 5 '-lipoxygenase and cyclo-oxygenase pathways, which are responsible for the production of eicosanoids, including leukotrienes and prostaglandins [1-3]. The lipid extract Lyprinol is rich in eicosapentaenoic acid and docosahexanoic acid, $\omega-3$ fatty acids that inhibit the metabolism of arachidonic acid [4]. This extract is effective in reducing pain, swelling and stiffness and in improving the functional index in patients with rheumatoid arthritis and osteoarthritis $[5,6]$. Its efficacy in the treatment of airway inflammation is unknown.

The aim of this study is to assess the effect of lipid extract of New Zealand green-lipped mussel on symptoms, peak expiratory flow (PEF) and hydrogen peroxide $\left(\mathrm{H}_{2} \mathrm{O}_{2}\right)$ in expired breath condensate as a marker of airway inflammation in patients with atopic asthma in a double-blind randomised, placebocontrolled clinical trial.

\section{Patients \\ Methods}

Volunteers aged 18-56 yrs with mild-to-moderate atopic asthma were recruited in the outpatients department of the Hospital Therapeutic Clinic, Pavlov Medical University, St-Petersburg, Russia (table 1). Patients were diagnosed according to the American Thoracic Society definition of asthma [7]. Diagnosis was based upon clinical history, reversibility of forced expiratory volume in one second (FEV1) of $>15 \%$ and diurnal variability of PEF of $>20 \%$. Atopic status was assessed by positive skinprick test $(>3 \mathrm{~mm})$ to common inhalant allergens (house-dust mite, animal allergens, pollen). All patients were sensitised to house-dust mite. Severity of asthma was classified according to the National Institutes of Health/World Health Organization (NIH/ WHO) guidelines [8]. Briefly, subjects with mild asthma had symptoms twice a week or less often with FEV1 $\geqslant 80 \%$ of predicted and used inhaled short-acting $\beta_{2}$-agonists for symptom relief. Patients with moderate asthma had daily symptoms and an FEV1 between 60 and $80 \%$ pred, and used inhaled short-acting $\beta_{2}$-agonists daily. Exclusion criteria were use of inhaled steroids within the previous 4 weeks, oral steroid treatment within the previous 3 months, current or exsmokers, clinically significant heart, renal, liver and intestinal disorders, women of childbearing potential not using adequate contraception. Only patients fully cooperative in all procedures were considered for inclusion in the run-in period of the trial.

The study was approved by the Local Ethics Committee and all participants gave written consent. 
Table 1. - Characteristics of patients with atopic asthma treated with Lyprinol and placebo

\begin{tabular}{lcc}
\hline Characteristics of patients & Placebo & Lyprinol \\
\hline Patients $n$ & 23 & 23 \\
Sex M:F & $5: 18$ & $7: 16$ \\
Age yrs & $37.4 \pm 2.2$ & $40.8 \pm 2.4$ \\
Duration of asthma yrs & $4.5 \pm 0.9$ & $7.3 \pm 1.2$ \\
FEV1\% \%red & $90.4 \pm 3.0$ & $82.9 \pm 4.2$ \\
Concomitant medications & Short-acting inhaled & Short-acting inhaled \\
& $\beta_{2}$-agonists as required & $\beta_{2}$-agonists as required \\
\hline
\end{tabular}

Data are expressed as mean \pm SEM. M: male; F: female; FEV1: forced expiratory volume in one second. Differences between two groups of asthmatic patients are not significant.

\section{Study design}

The study was a single-centre, double-blind, parallelgroup, randomised, placebo-controlled trial. Patients who fulfilled the inclusion criteria at the initial visit entered a 2 week observation run-in period, in which regular treatment was stopped and short-acting $\beta_{2^{-}}$ agonists (salbutamol or terbutaline) as required were the only medications allowed. Asthma symptoms and use of rescue medications were recorded in a diary. Patients were excluded if they received inhaled steroids or were hospitalised for asthma during the run-in period.

After the run-in period patients were randomly assigned to receive either lipid extract of New Zealand green-lipped mussel, two capsules twice daily or matching placebo for a period of 8 weeks. Each lipid extract capsule contained $50 \mathrm{mg} \omega-3$ polyunsaturated fatty acids (eicosapentaenoic acid and docosahexaenoic acid) and $100 \mathrm{mg}$ olive oil (Lyprinolß, Mac Lab, Melbourne, Australia). Each identical placebo capsule contained $150 \mathrm{mg}$ olive oil only. Randomisation was computer-generated in balanced blocks of two treatment regimens. Inhaled salbutamol delivered via pressurised metered-dose inhaler or terbutaline delivered by dry powder inhaler (Turbuhaler) were used as rescue medications throughout the study. No other medications were allowed. All short-acting inhaled $\beta_{2}$-agonists were stopped at least $6 \mathrm{~h}$ before baseline FEV1 and exhaled $\mathrm{H}_{2} \mathrm{O}_{2}$ measurements.

\section{Measurements}

Subjects kept a twice-daily dairy card throughout the study. They were provided with individual peakflow meters (Vitalograph Ltd, Buckingham, UK). The best of three peak flow values was recorded before taking the morning and evening study medications. Patients recorded daytime wheeze, nocturnal awakenings from asthma, daily use of short-acting inhaled $\beta_{2}$-agonists and compliance with the study medications. Asthma symptoms were ranked on a scale from 0 (none) to 3 (very uncomfortable and interferes with normal activities). At the beginning and the end of the study, subjects attended the research clinic for measurement of FEV1, which was measured by dry spirometry (Vitalograph Ltd). The concentration of exhaled $\mathrm{H}_{2} \mathrm{O}_{2}$ was measured at the beginning of the study, and at 4 and 8 weeks of treatment. Study medications and inhaled short-acting $\beta_{2}$-agonists were withheld for at least $6 \mathrm{~h}$ before spirometry and exhaled $\mathrm{H}_{2} \mathrm{O}_{2}$ measurements.

Expired breath condensate was collected using a glass condensing device, which was placed in a large chamber with ice as previously described [9]. After mouth rinsing, subjects breathed tidally through a mouthpiece for $20 \mathrm{~min}$ while wearing a nose-clip. The mouthpiece was also used as a saliva trap. The volume of condensate was $2-4 \mathrm{~mL}$ and $\mathrm{H}_{2} \mathrm{O}_{2}$ was assayed immediately. $\mathrm{H}_{2} \mathrm{O}_{2}$ was measured by using a colorimetric assay as described previously [10]. Briefly, $100 \mu \mathrm{L}$ of condensate was mixed with $100 \mu \mathrm{L}$ of $3,3^{\prime}, 5,5^{\prime}$ tetramethylbenzidine in $0.42 \mathrm{M}$ citrate buffer, $\mathrm{pH} 3.8$, and $10 \mu \mathrm{L}$ of horseradish peroxidase $\left(52.5 \mathrm{U} \cdot \mathrm{m}^{-1}\right)$. The samples were incubated at room temperature for $20 \mathrm{~min}$ and the reaction stopped by the addition of $10 \mu \mathrm{L} 18 \mathrm{~N}$ sulphuric acid. The reaction product was measured spectrophotometrically (Model 46; Lomo Inc., St-Petersburg, Russia) at $450 \mathrm{~nm}$. A standard curve of $\mathrm{H}_{2} \mathrm{O}_{2}$ was performed for each assay.

\section{Safety of the treatment}

At each visit subjects were specially asked for any adverse events and health problems that may have occurred. All unusual signs and symptoms were recorded for further consideration. The safety of the treatment was evaluated by monitoring blood pressure, concentrations of creatinine, bilirubin, activity of liver transaminases and alkaline phosphatase in serum at clinical visits.

\section{Analysis of data}

Paired and unpaired two-tailed t-tests were used for statistical analysis. A p-value $<0.05$ was considered significant, and the data are expressed as mean \pm SEM.

\section{Results}

\section{Subjects}

Of 60 volunteers recruited to the study, 46 fulfilled the entry criteria and were randomised to treatment. The most common reason for withdrawal before randomisation was deterioration in asthma control (14 subjects). These patients had a lower FEV1 
$(70.3 \pm 2.1 \%$ pred $)$ than those who were randomised $(87.60 \pm 2.5, \mathrm{p}<0.001)$. All randomised patients completed the treatment and were included in the statistical analysis. Thirty six of them had mild asthma and 10 patients had moderate asthma.

\section{Compliance}

The mean self-recorded compliance with the twotimes daily study medications (Lyprinol or placebo) was $95 \%$ and $93 \%$, respectively.

\section{Asthma symptoms and bronchodilator use}

Mean daytime wheeze was significantly reduced in patients treated with Lyprinol compared to those treated with placebo (table 2). There were no significant differences between the two treatment groups in respect to nocturnal awakening and use of short-acting $\beta_{2}$-agonists (table 2 ).

\section{Lung function tests}

Mean FEV1 and evening PEF during the treatment with Lyprinol did not significantly differ from those during the treatment with placebo. However, mean morning PEF was significantly higher during the treatment with Lyprinol than with placebo (table 2).

\section{Exhaled hydrogen peroxide}

Mean concentrations of exhaled $\mathrm{H}_{2} \mathrm{O}_{2}$ were significantly reduced during the treatment with Lyprinol compared to placebo (table 2).

Table 2.-Efficacy results

\begin{tabular}{|c|c|c|c|}
\hline Parameters & Placebo & Lyprinol & $\mathrm{p}$-value \\
\hline Patients $\mathrm{n}$ & 23 & 23 & \\
\hline \multicolumn{4}{|c|}{ Daytime wheeze } \\
\hline Baseline & $1.41 \pm 0.42$ & $2.27 \pm 0.36$ & 0.131 \\
\hline 4 week & $1.23 \pm 0.26$ & $1.07 \pm 0.23$ & 0.637 \\
\hline$\Delta$ & $-0.17 \pm 0.33$ & $-1.20 \pm 0.24$ & 0.023 \\
\hline 8 week & $1.29 \pm 0.17$ & $0.73 \pm 0.21$ & 0.041 \\
\hline$\Delta$ & $-0.11 \pm 0.43$ & $-1.53 \pm 0.42$ & 0.026 \\
\hline \multicolumn{4}{|c|}{ Night awakenings } \\
\hline Baseline & $0.69 \pm 0.24$ & $1.09 \pm 0.16$ & 0.195 \\
\hline 4 week & $0.54 \pm 0.18$ & $0.45 \pm 0.16$ & 0.737 \\
\hline$\Delta$ & $-0.15 \pm 0.27$ & $-0.64 \pm 0.20$ & 0.184 \\
\hline 8 week & $0.61 \pm 0.14$ & $0.36 \pm 0.20$ & 0.308 \\
\hline$\Delta$ & $-0.08 \pm 0.29$ & $-0.73 \pm 0.19$ & 0.085 \\
\hline \multicolumn{4}{|c|}{ Usage of $\beta_{2}$-agonists puffs $\cdot$ day $^{-1}$} \\
\hline Baseline & $2.17 \pm 0.64$ & $3.17 \pm 0.56$ & 0.252 \\
\hline 4 week & $1.92 \pm 0.43$ & $1.92 \pm 0.78$ & 1.0 \\
\hline$\Delta$ & $-0.25 \pm 0.52$ & $-1.25 \pm 0.55$ & 0.202 \\
\hline 8 week & $2.00 \pm 0.48$ & $1.58 \pm 0.42$ & 0.253 \\
\hline$\Delta$ & $-0.17 \pm 0.38$ & $-1.59 \pm 0.60$ & 0.022 \\
\hline \multicolumn{4}{|c|}{ FEV $1 \%$ pred } \\
\hline Baseline & $92.32 \pm 2.9$ & $82.89 \pm 4.2$ & 0.073 \\
\hline 8 week & $90.53 \pm 3.2$ & $82.87 \pm 3.6$ & 0.124 \\
\hline \multirow{2}{*}{\multicolumn{4}{|c|}{ Morning PEF $\mathrm{L} \cdot \mathrm{min}^{-1}$}} \\
\hline & & & \\
\hline Baseline & $384.3 \pm 21.5$ & $361.3 \pm 17.4$ & 0.409 \\
\hline 28 day & $376.0 \pm 26.0$ & $392.2 \pm 18.9$ & 0.619 \\
\hline$\Delta$ & $-8.3 \pm 9.4$ & $30.9 \pm 13.6$ & 0.022 \\
\hline 56 day & $350.9+21.3$ & $408.3+18.7$ & 0.049 \\
\hline$\Delta$ & $-33.4 \pm 6.2$ & $47.0 \pm 11.7$ & 0.00001 \\
\hline \multicolumn{4}{|c|}{ Evening PEF $\mathrm{L} \cdot \mathrm{min}^{-1}$} \\
\hline Baseline & $399.6 \pm 16.7$ & $375.4 \pm 18.2$ & 0.333 \\
\hline 4 week & $395.9 \pm 23.0$ & $404.8 \pm 17.1$ & 0.758 \\
\hline$\Delta$ & $-3.7 \pm 11.4$ & $29.4 \pm 11.5$ & 0.047 \\
\hline 8 week & $403.9 \pm 18.3$ & $406.5 \pm 19.7$ & 0.923 \\
\hline$\Delta$ & $4.3 \pm 10.3$ & $31.1 \pm 14.6$ & 0.136 \\
\hline \multicolumn{4}{|c|}{ Exhaled $\mathrm{H}_{2} \mathrm{O}_{2} \mu \mathrm{M}$} \\
\hline Baseline & $0.12 \pm 0.04$ & $0.11 \pm 0.02$ & 0.706 \\
\hline 4 week & $0.11 \pm 0.02$ & $0.07 \pm 0.01$ & 0.072 \\
\hline$\Delta$ & $-0.01 \pm 0.03$ & $-0.04 \pm 0.02$ & 0.509 \\
\hline 8 week & $0.16 \pm 0.04$ & $0.05 \pm 0.01$ & 0.022 \\
\hline$\Delta$ & $0.04 \pm 0.05$ & $-0.06 \pm 0.01$ & 0.0001 \\
\hline
\end{tabular}

Data are expressed as mean \pm SEM. $\Delta$ : change from baseline value; FEV1: forced expiratory volume in one second; PEF: peak expiratory flow; $\mathrm{H}_{2} \mathrm{O}_{2}$ : hydrogen peroxide. Asthma symptoms were ranked on a scale from 0 (none) to 3 (very uncomfortable and interferes with normal activities). 


\section{Safety of the treatment}

One patient treated with Lyprinol and one patient treated with placebo had skin itch. One patient in the Lyprinol group and two patients in the placebo group complained of a metallic taste. There were no significant changes in blood pressure, or in concentrations of serum creatinine, bilirubin, liver transaminases or alkaline phosphatase in either group of patients (data not shown).

\section{Discussion}

The data from this study show that a stabilised lipid extract of New Zealand green-lipped mussel, Perna canaliculus (Lyprinol), reduces daytime wheeze and improves morning PEF in steroid-naïve patients with atopic asthma compared to placebo. There were no differences between patients treated with Lyprinol and placebo with respect to FEV1. It should be noted that most of the patients had mild asthma and FEV $1>80 \%$ pred and thus there was little room for improvement in this measurement.

Lyprinol was well tolerated and had very few side-effects. The findings of the present study are in agreement with a previously published study [1].

The mechanism by which lipid extract of New Zealand green-lipped mussels exerts its beneficial effect remains to be elucidated. Lyprinol inhibits leukotriene production by stimulated human polymorphonuclear leukocytes in vitro [2]. Much of this activity was associated with its content of $\omega-3$ polyunsaturated fatty acids (eicosapentaenoic acid and docosahexaenoic acid) and antioxidants such as carotenoids. $\omega-3$ polyunsaturated acids inhibit arachidonate metabolism by $5^{\prime}$-lipoxygenase and cyclo-oxygenase [6], thus reducing the formation of leukotrienes and prostaglandins. Dietary supplementation with $\omega-3$ polyunsaturated fatty acids can suppress synthesis of interleukin-1 and tumour necrosis factor- $\alpha$ by mononuclear cells [11]. Epidemiological studies in Inuit, Dutch [12], American [13], Australian [14] and Japanese populations [15] have shown that a high dietary intake of $\omega-3$ polyunsaturated fatty acids is associated with lower incidence of cardiovascular disease and inflammatory diseases, such as asthma and rheumatoid arthritis. Dietary supplementation with fish oil rich in the $\omega-3$ polyunsaturated fatty acids over a 10 -month period is beneficial in children with asthma following a strictly controlled diet and controlled allergen exposure [16].

Leukotrienes are mediators of airway inflammation in asthma. They induce bronchoconstriction and airway smooth muscle proliferation $[17,18]$, stimulate mucus secretion [19], increase microvascular permeability and cause infiltration of inflammatory cells such as eosinophils and neutrophils into the airways $[20,21]$. These cells release superoxide anions which then undergo spontaneous or enzyme-catalysed dismutation to form $\mathrm{H}_{2} \mathrm{O}_{2} . \mathrm{H}_{2} \mathrm{O}_{2}$ is a highly reactive oxygen species involved in cellular injury via further reactions leading to hydroxyl radical and lipid peroxidation products [22]. Increased production of free radicals occurs in airway inflammation, and $\mathrm{H}_{2} \mathrm{O}_{2}$ is detectable in exhaled air [23].

Several studies have shown that $\mathrm{H}_{2} \mathrm{O}_{2}$ in expired breath condensate may be a nondirect marker of oxidative stress and airway inflammation in asthmatic patients $[24,25]$. Exhaled $\mathrm{H}_{2} \mathrm{O}_{2}$ levels have previously been related to the eosinophil differential counts in induced sputum and activity of peripheral neutrophils in asthmatic patients $[25,26]$. Therefore, elevated concentrations of $\mathrm{H}_{2} \mathrm{O}_{2}$ may result from an enhanced number and activity of inflammatory cells in the airways.

In the present study, the authors found that elevated concentrations of exhaled $\mathrm{H}_{2} \mathrm{O}_{2}$ were significantly decreased during treatment with Lyprinol compared to placebo. This may result from a reduction in the number of inflammatory cells in asthmatic airways because of decreased synthesis of leukotrienes and may also be due to the antioxidants such as $\beta$-carotene contained in Lyprinol.

In conclusion, this study shows that a lipid extract of New Zealand green-lipped mussel may have some beneficial effects in patients with steroid-naïve atopic asthma. Further clinical studies are needed to determine whether it may be useful as a supplement to other medications in the treatment of asthmatic patients.

\section{References}

1. Whitehouse MW, Macrides TA, Kalfatis NK, Betts WH, Haynes DR, Broadbent J. Anti-inflammatory activity of a lipid fraction (Lyprinol) from the NZ green-lipped mussel. Inflammopharmacology 1997; 5: 237-246.

2. Rainsford KD, Whitehouse MW. Gastroprotective and anti-inflammatory properties of green-lipped mussel (Perna canaliculus) preparation. Arzn Forsch 1980; 30: 2128-2132.

3. Halpern G-M. Anti-inflammatory effects of a stabilized lipid extract of Perna Canaliculus (Lyprinol®). Allerg Immunol (Paris) 2000; 32: 272-278.

4. Sinclair AJ, Murphy KJ, Li D. Marine lipids: overview "news insights and lipid composition of Lyprinol". Allerg Immunol (Paris) 2000; 32: 261-271.

5. Gibson SLM, Gibson RG. The treatment of arthritis with lipid extract of Perna canaliculus: a randomized trial. Compl Ther Med 1998; 6: 122-126.

6. Gibson RG, Gibson S, Conway V, Chappel D. Perna canaliculus in the treatment of arthritis. Practitioner 1980; 224: 955-960.

7. American Thoracic Society. Standards for the diagnosis and care of patients with chronic obstructive pulmonary disease (COPD) and asthma. Am Rev Respir Dis 1987; 136: 225-244.

8. Diagnosis and classification. In: Global Initiative for asthma. NHLB/WHO Workshop Report. Publication number 95-3659. USA, National Heart Lung Blood Institute, 1995; pp. 48-61.

9. Emelyanov A, Fedoseev G, Abulimity A, et al. Elevated concentrations of exhaled hydrogen peroxide in asthmatic patients. Chest 2001; 120: 1136-1139.

10. Gallati H, Pracht I. Horseradish peroxidase: kinetic studies and optimisation of peroxide activity 
determination using the substrates $\mathrm{H}_{2} \mathrm{O}_{2}$ and $3,3^{\prime}, 5,5^{\prime}$ tetramethybenzidine. J Clin Chem Clin Biochem 1985; 23: 453-460.

11. Endres S, Ghorbani R, Kelly VE, et al. The effect of dietary supplementation with $\omega-3$ polyunsaturated fatty acids on the synthesis of interleukin- 1 and tumor necrosis factor by mononuclear cells. $N$ Engl J Med 1989; 320: 265-271.

12. Kromann N, Green A. Epidemiological studies in the Upernavik district, Greenland. Incidence of some chronic diseases 1950-1974. Acta Med Scan 1980; 208: 401-406.

13. Schwartz J, Weiss ST. The relationship of dietary fish oil intake to level of pulmonary function in the first National Health and Nutritional Survey. Eur Respir J 1994; 7: 1821-1824.

14. Peat JK, Salome CM, Woolcock AJ. Factors associated with bronchial hyperresponsiveness in Australian adults and children. Eur Respir J 1992; 5: 921-929.

15. Satomi $H$, Minowa $M$, Hatano S, Iikura $Y$. An epidemiological study of the preventive effect of dietary fish on bronchial asthma. Bull Inst Public Health 1994; 43: 305-314.

16. Nagakura T, Matsuda S, Shichijyo K, Sugimoto H, Hata K. Dietary supplementation with fish oil rich in $\omega-3$ polyunsaturated fatty acids in children with bronchial asthma. Eur Respir J 2000; 16: 861-865.

17. Piper PJ. Leukotrienes: potent mediators of airway constriction. Int Arch Allergy Appl Immunol 1985; 76: Suppl. 1, 43-48.

18. Wang CG, Du T, Xu LJ, Martin JG. Role of leukotriene $\mathrm{D}_{4}$ in allergen-induced increases in airway smooth muscle in rat. Am Rev Respir Dis 1994; 148: 413-417.
19. Marom Z, Shelhamer JH, Bach MK, Morton DR, Kaliner M. Slow-reacting substances leukotriene $\mathrm{C}_{4}$ and $\mathrm{D}_{4}$, increase the release of mucus from human airway in vitro. Am Rev Respir Dis 1982; 126: 449-451.

20. Dahlen S-E, Bjorck, Heaqvist P, et al. Leukotrienes promote plasma leakage and leukocyte adhesion in post-capillary venules: in vitro effects with relevance to the acute inflammatory response. Proc Natl Acad Sci USA 1981; 78: 3887-3891.

21. Laitinen LA, Laitinen A, Haahtela T, Vilkka V, Spur $\mathrm{BW}$, Lee $\mathrm{TH}$. Leukotriene $\mathrm{E}_{4}$ cause granulocyte infiltration into asthmatic airway. Lancet 1993; 341: 989-990.

22. Mates JM, Sanchez-Jimenez F. Antioxidant enzymes and their implications in pathophysiologic processes. Front Biosci 1999; 4: 339-345.

23. Kharitonov SA, Barnes PJ. Exhaled markers of pulmonary diseases. Am J Respir Crit Care Med 2001; 163: 1693-1722.

24. Antzak A, Nowak D, Shariati B, Krol M, Piasecka G, Kurmanowska Z. Increased hydrogen peroxide and thiobarbituric acid-reactive products in expired breath condensate of asthmatic patients. Eur Respir J 1997; 9: $1235-1241$.

25. Horvath I, Donnely LE, Kiss A, et al. Combined use of exhaled hydrogen peroxide and nitric oxide in monitoring asthma. Am J Respir Crit Care Med 1998; 158: $1042-1046$.

26. Antzak A, Nowak D, Bialasiewicz P, Kasielski M. Hydrogen peroxide in expired air condensate correlates positively with early steps of peripheral neutrophil activation in asthmatic patients. Arch Immunol Ther Exp (Warsz) 1999; 47: 119-126. 